\title{
Appraising Adequacy of Standard Based Curriculum 2006 and Allied Secondary School Mathematics Textbooks for Higher Order Thinking Skills (HOTS) in the Punjab, Pakistan
}

\author{
Khurram Gulzar* \\ Nasir Mahmood $^{* *}$
}

\begin{abstract}
In Pakistan the curriculum was revised in 2005-06 and corresponding textbooks for secondary school mathematics were developed and adopted for session 2012-13. This study was conducted to analyze the adequacy of the curriculum and the newly adopted textbooks in instilling the HOTS in students. The research design used was descriptive in which data was analyzed both by qualitative and quantitative methods. Web Alignment Tool was used to assign Depth of knowledge (DOK) levels to the prescribed students learning outcomes (SLOs) for secondary level mathematics in Pakistan. The outcomes of the study show that the curriculum is predominated by the SLOs of DOK level 1(204 out 280 SLOs). There is no SLO of DOK level 4. There are 70 SLOs of DOK level 2 and only six SLOs of DOK level 3. The entire format of the textbooks is monotonous as it mostly guides the students to learn an algorithm to deal with any SLO. This is followed by an exercise of sums to practice the learnt algorithm without any appropriate learning experience. It is suggested to revise the respective curriculum by adopting fewer, higher and deeper approach. For DOK level 2 and above, appropriate learning experiences should be incorporated in the curriculum and textbooks.
\end{abstract}

Keywords: HOTS, educational alignment, Mathematics textbooks

\footnotetext{
*Ph.D Scholar, Institute of Education \& Research University of the Punjab Lahore, Pakistan, Email: khurram.ier@hotmail.com

** Professor, Department of Early Childhood and Elementary Teacher Education, AIOU, Email: mahsir1@yahoo.com
} 


\section{Introduction}

At secondary level, the primary purpose of teaching learning process defensibly is to prepare students for further studies and/or career readiness for which educational standards are so designed that they refine critical thinking of students (Anderson \& Mills, 2015). In Pakistan, the curriculum was revised in 2005-06 with the intention to "make it comparable with the international standards" (Ministry of Education [MoE], 2006) and the instructional material i.e. the textbooks designed as per the standard based curriculum 2006/07 was adopted at secondary level for the session 201213. The said secondary school mathematics curriculum comprised five standards which were divided into 35 benchmarks for which 280 corresponding students learning outcomes/skills (SLOs) were defined (MoE, 2006). The textbooks for grade IX and X were prepared in accordance with those SLOs

According to MoE (2006), the intention behind adopting the standard based curriculum was to make it responsive to the needs of international labor market by making it comparable to the international standards. And Churches (2009) has stated that in the 21st Century the focus of teaching learning process has shifted from lower order thinking skills towards higher order thinking. It was therefore necessary to assess how far the newly adopted curriculum was capable of developing Higher Order Thinking Skills [HOTS] in students. It is generally perceived that evaluating curriculum with regard to its capacity to develop HOTS in students suffices for the purpose, but in Pakistan, textbooks are a must part of teaching learning process even up to higher secondary level. Government of Pakistan acknowledged them to be the only source of learning material available in most part of the country including the Punjab (Mahmood, 2010). Therefore, given the Pakistani scenario where textbooks are used as fundamental tool of teaching at secondary level and those textbooks in turn, have been developed in the light of standard based curriculum 2006, the comprehensive view of matter could not be obtained without evaluating textbooks, along with curriculum.

A standardized tool, called Webb Alignment Tool, was used to judge how much the curriculum 2006 is capacitated with HOTS. To evaluate the adequacy of textbooks, their contents were reviewed to identify the activities that might instill HOTS in the students. 


\section{Literature Review}

According to Musfiqi and Jailani (2015) HOTS can generally be defined as critical and creative thinking, that is, the skill of processing the available information in order to face a new situation or to solve a given problem. In pursuance of sorting the cognition in terms of lower and higher order thinking skills, Benjamin S. Bloom was the first in the history who used the term taxonomy (Forehand, 2010) for a framework of classification of the cognitive expectations. It was tiered organization of educational objectives (Ursani, Memon, \& Chowdhry, 2014) that was developed to determine the alignment between the educational objectives and corresponding learning activities and assessments (Krathwohl, 2002).

Despite its undeniable contribution to the educational practices, Bloom's taxonomy was questioned and revised for its oversimplification of the nature of thinking process and its relationship to learning (Marzano, R.J; Kendall J. S, 2006). It used verbs to differentiate the taxonomy levels and as the verbs generally appear at multiple levels of the taxonomy so it was difficult to infer the intended complexity of the allied level of the taxonomy (Hess, Jones, Carlock, \& Walkup, 2009). HOTS pertain to the level of cognitive complexity and work of Norman Webb is arguably the best in this area of Depth of knowledge (Council of Chief State School Officers, 2002; Hess, Carlock, Jones, \& Walkup, 2009) that caters for the limitation of Bloom's taxonomy.

According to Webb (2005) Depth of Knowledge (DOK) pertains to the complexity of an educational objective rather than its difficulty. The focus of Bloom is the categorization of the cognitive skills while performing tasks (Anderson \& Mills, 2015; Hess, Carlock et al., 2009; Hess, Jones, et al., 2009), whereas Webb compares the complexity of the content with the complexity of the task that is used to assess the learning of the content. He has defined four levels of cognitive expectations and named them as recall and reproduction, skills or concept, strategic thinking and extended thinking.

A brief description of the four levels of DOK is as follows:

Level 1 is called recall and reproduction. It is about recalling of information. This recall could be of a fact, term or a definition. It could be a simple procedure to be performed. Any student answering a Level 1 question either knows the answer or does not know it. 
Level 2 is named as skills or concepts. This level is about engaging a student in some sort of mental processing that is beyond, mere recalling of information. Selecting a procedure to solve a problem, using some information to construct a response, are examples of Level 2 activities. This mental processing makes this level more complex than Level 1.

Level 3 is called strategic thinking. This level requires planning, reasoning, using evidence, etc. Activities like developing a plan to solve a given problem or justifying one's decision taken to solve a particular task makes Level 3 a higher level of thinking than Level 1 and 2.

Level 4 is called extended thinking. Tasks at this level demand higher level of cognitive skills. Students have to relate ideas, opt or develop one approach among many possible solutions. Activities of this level require complex reasoning, developing of experimental designs, and usually require an extended period of time for thinking and application.

\section{Research Questions}

This study was conducted to find the answers of the following research questions:

i. How much is the standard based curriculum of secondary level mathematics focused upon higher order thinking skills of students of Pakistan?

ii. How much are the textbooks helpful to the students to develop the higher order thinking skills as expected in the standard based curriculum of secondary level mathematics of the Punjab, Pakistan?

\section{Methodology}

This paper was extracted from an ongoing doctoral research work of one of the researchers of this study.

\section{Research Design}

The research design used in this study was descriptive and explanatory case study in which data was analyzed both by qualitative and quantitative methods. 


\section{Instrument}

Webb based standardized tool called Webb alignment tool was used to assess the SLOs of curriculum 2006 with regard to their DOK level.

\section{Procedure}

To estimate the magnitude of HOTS in the secondary mathematics of Pakistan, a standardized Webb Alignment Tool (WAT(v2)) was used. The WAT (v2) is an Internet application that is used "to automate the process of gauging alignment between standards and assessments "(Webb, 2005, p. 7). As recommended by Webb, five content experts were involved as reviewers to assign Depth of knowledge (DOK) level to the SLOs for the secondary school mathematics in the standard based curriculum of Pakistan. The reviewers individually judged and assigned the DOK level to the entire 280 SLOs using the WAT (v2) application. Afterwards, the consensus was developed about the DOK level of every SLO and entered in the WAT (v2). The snapshot of the consensus about the SLOs for grade $\mathrm{IX}$ and $\mathrm{X}$ are attached with this paper as annexure $\mathrm{A}$ and $\mathrm{B}$.

To estimate the adequacy of the textbooks the contents of the textbooks for grade IX and X by Dar \& Haq(2012) and Habib, Ali, Rauf, $\&$ Moeen (2013) were reviewed. As literature suggests to engage the students in challenging and research oriented activities to develop their HOTS (Healey, 2005; Patterson et al., 2013; Harding \& Hbaci, 2015) so the textbooks contents were reviewed with the view to identify the activities suitable for inquiry based learning, scaffolding etc.

\section{Results and Discussion}

Based on the reviewers' work the Table 1 contains the summary of consensus data about the DOK level of the 280 SLOs for the secondary school mathematics. 
Table 1

Consensus Data about DOK Level of SLOs for Secondary School Mathematics

\begin{tabular}{lccccc}
\hline & $\begin{array}{c}\text { DOK } \\
\text { Level 1 } \\
\text { (Recall) }\end{array}$ & $\begin{array}{c}\text { DOK Level 2 } \\
\text { (Skill/Concept) }\end{array}$ & $\begin{array}{c}\text { DOK } \\
\text { Level 3 } \\
\text { Strategic } \\
\text { Thinking) }\end{array}$ & $\begin{array}{c}\text { DOK } \\
\text { Level 4 } \\
\text { Extended } \\
\text { Thinking) }\end{array}$ & $\begin{array}{c}\text { Total } \\
\text { SLOs in } \\
\text { the } \\
\text { Textbook }\end{array}$ \\
\hline $\begin{array}{l}\text { Grade IX } \\
\text { Textbook }\end{array}$ & 97 & 41 & 4 & 0 & 142 \\
\hline $\begin{array}{l}\text { Grade X } \\
\text { Textbook }\end{array}$ & 107 & 29 & 2 & 0 & 138 \\
\hline Total & 204 & 70 & 6 & 0 & 280 \\
\hline
\end{tabular}

Note: As agreed upon by five reviewers, columns two to five show DOK levels of 142 and 138 SLOs of grade IX and grade X Mathematics textbooks. DOK = Depth of Knowledge

\section{HOTS in Secondary Mathematics}

Figure 1 describes the comparison of complexity of SLOs within as well as across the grades IX and X. More focus on HOTS is expected in a higher grade but the complexity levels of grade X SLOs don't seem to meet this criterion.

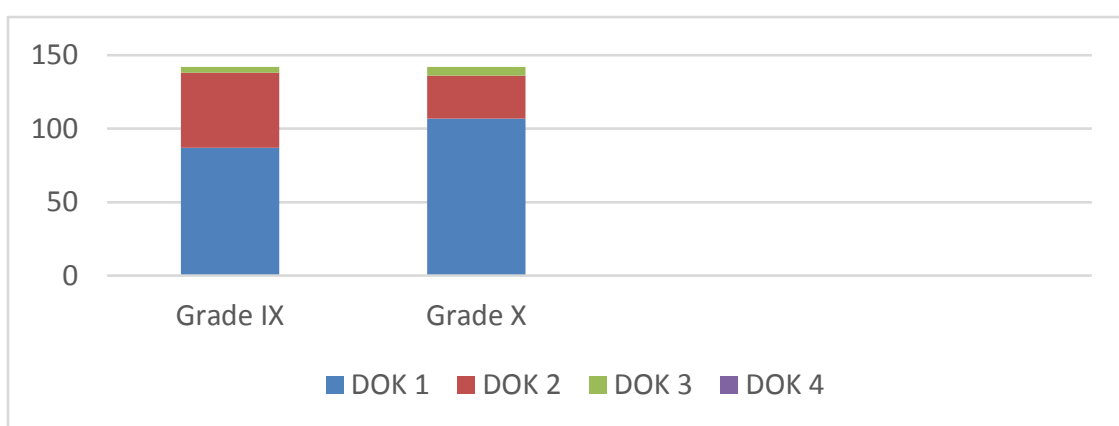

Figure 1: DOK levels of Secondary School Mathematics Curriculum. DOK = Webb's Depth of Knowledge; DOK 1 = Total competencies at first level; DOK 2 $=$ Total competencies at second level; DOK $3=$ Total competencies at third level; DOK $4=$ Total competencies at fourth level

There are neither fixed guidelines regarding "an acceptable progression in content complexity from grade to grade" (Webb, 2007, 
p.22), nor any standardized criteria about weightage of HOTS in the overall composition of a curriculum; nevertheless, balance between LOTS and HOTS, is perhaps minimally expected. Admittedly almost every grade contains Lower Order Thinking Skills (LOTS), yet to foster the critical thinking, the focus of the allied curriculum must be the HOTS (Anderson \& Mills, 2015; Patterson et al., 2013; Skinner \& Feder, 2014). But it is evident from Figure 2 that the overall composition of secondary mathematics curriculum is explicitly predominated by the DOK level 1 based expectations i.e. the LOTS. It is notable that $73 \%$ of the SLOs are at the lowest level, which is DOK level 1.

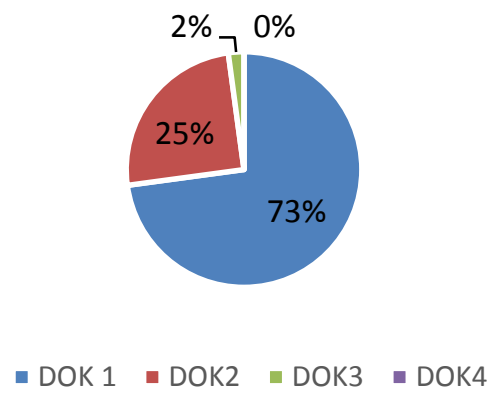

Figure 2. Secondary School Mathematics Curriculum-Overall Percent of DOK Levels (Grade IX \& X). DOK = Webb's Depth of Knowledge; DOK $1=$ Percentage of Total competencies at first level; DOK $2=$ Percentage of Total competencies at second level; DOK $3=$ Percentage of Total competencies at third level; DOK 4 = Percentage of Total competencies at fourth level

\section{Textbooks Adequacy}

As stated in the Table 1, according to consensus of reviewers, there were 70 SLOs of DOK Level 2 and six SLOs of DOK Level 3 in the entire set of 280 SLOs against which grade IX and X textbooks were prepared. Table 2 and Table 3 were developed in the light of Hess, Jones, et al. (2009) explanation of Webb's DOK levels to understand how the reviewers would have rated 70 SLOs of DOK Level 2 and six SLOs as of DOK Level 3. 
Table 2

Categories of SLOs of DOK Level 2 in Secondary Mathematics Textbooks

\begin{tabular}{|c|c|c|}
\hline Category & Description & $\begin{array}{l}\text { Relevance with DOK } \\
\text { Level } 2\end{array}$ \\
\hline $\begin{array}{l}\text { Verifying a } \\
\text { law/formula }\end{array}$ & $\begin{array}{l}\text { These SLOs demand } \\
\text { students to provide } \\
\text { relevant examples to } \\
\text { verify a law }\end{array}$ & $\begin{array}{l}\text { Students have to be } \\
\text { engaged in some mental } \\
\text { processing (Webb, 2002) } \\
\text { in order to produce the } \\
\text { relevant example. }\end{array}$ \\
\hline $\begin{array}{l}\text { Proving a law or } \\
\text { theorem of } \\
\text { algebra/Derive a } \\
\text { formula }\end{array}$ & $\begin{array}{l}\text { These SLOs demand } \\
\text { students to follow } \\
\text { some logical } \\
\text { mathematical steps in } \\
\text { order to prove a } \\
\text { law/theorem or derive } \\
\text { a formula }\end{array}$ & $\begin{array}{l}\text { Students have to "select } \\
\text { appropriate procedures for } \\
\text { a task" (Hess, Jones, et al., } \\
\text { 2009) }\end{array}$ \\
\hline $\begin{array}{l}\text { Applying a } \\
\text { law/formula/ } \\
\text { Theorem }\end{array}$ & $\begin{array}{l}\text { These SLOs demand } \\
\text { students to select the } \\
\text { appropriate } \\
\text { law/formula or } \\
\text { theorem to solve a } \\
\text { given problem }\end{array}$ & $\begin{array}{l}\text { Students have to "select } \\
\text { appropriate } \\
\text { procedures...[laws, } \\
\text { formulae, or theorems].. } \\
\text { for a task"(Hess, Jones, et } \\
\text { al., 2009), or problem at } \\
\text { hand }\end{array}$ \\
\hline $\begin{array}{l}\text { Making/Using } \\
\text { graph }\end{array}$ & $\begin{array}{l}\text { These SLOs demand } \\
\text { students to organize } \\
\text { and display data in } \\
\text { graph and/or interpret } \\
\text { data displayed in } \\
\text { graph. }\end{array}$ & $\begin{array}{l}\text { Students have to } \\
\text { "organize or display data; } \\
\text { interpret or use simple } \\
\text { graphs" (Hess, Jones, et } \\
\text { al., 2009) }\end{array}$ \\
\hline $\begin{array}{l}\text { Proving a theorem } \\
\text { of geometry }\end{array}$ & $\begin{array}{l}\text { These SLOs demand } \\
\text { students to provide } \\
\text { already proved } \\
\text { theorems or axioms as } \\
\text { arguments in the } \\
\text { process to prove a new } \\
\text { statement of a theorem }\end{array}$ & $\begin{array}{l}\text { Students have to apply the } \\
\text { skill of "the integration } \\
\text { and application of } \\
\text { concepts" (Haladyna, T. } \\
\text { M., \& Downing, S. M., } \\
\text { 2006, p.166) to prove a } \\
\text { new theorem }\end{array}$ \\
\hline
\end{tabular}

Note. Similar set of SLOs are kept in the same category and are listed in first column. Second column shows expected students' activities against those SLOs and third column shows how those students' activities are of DOK level 2 activities. 
In Table 2 for instance, there is a category of SLOs about verifying $a$ law/formula. To verify a law or formula students are required to think of and reproduce relevant examples that help in verifying that law or formula. And according to Hess, Jones, et al. DOK level 2 activity engages students in mental processing to provide relevant examples.

Table 3

Category of SLOs of DOK Level 3 in Secondary Mathematics Textbooks

\begin{tabular}{lll}
\hline Category & Description & Relevance with DOK Level 3 \\
\hline Solving & These SLOs demand & Students have to "reason \\
real life & students to choose & ..to approach a problem; \\
problems & appropriate method and & employ some decision- \\
& plan to approach a real & making and justification; \\
& life problem & $\begin{array}{l}\text { solve abstract, complex, or } \\
\text { non-routine problems" } \\
\end{array}$ \\
& & (Hess, Jones, et al, 2009)
\end{tabular}

Note. Similar set of SLOs are kept in the same category and are listed in first column. Second column shows expected students' activities against those SLOs and third column shows how those students' activities are of DOK level 2 activities.

In Asia, mathematics curriculum of Singapore is considered one of the better curriculums (Hofer, 2015) and it emphasizes on the classroom experiences for enhancing the HOTS of students. For instance, it recommends the use of "paper folding to visualize symmetric properties of circles, e.g. the perpendicular bisector of chord passes through the centre" (Singapore Ministry of Education, 2012, p.47). In contrast, neither the Pakistani curriculum demands nor the textbooks provide any kind of learning experiences to its students. This is evident from figure 3 , a snapshot of secondary mathematics textbook by Habib et al. (2013), in which the same concept is explained to students. 


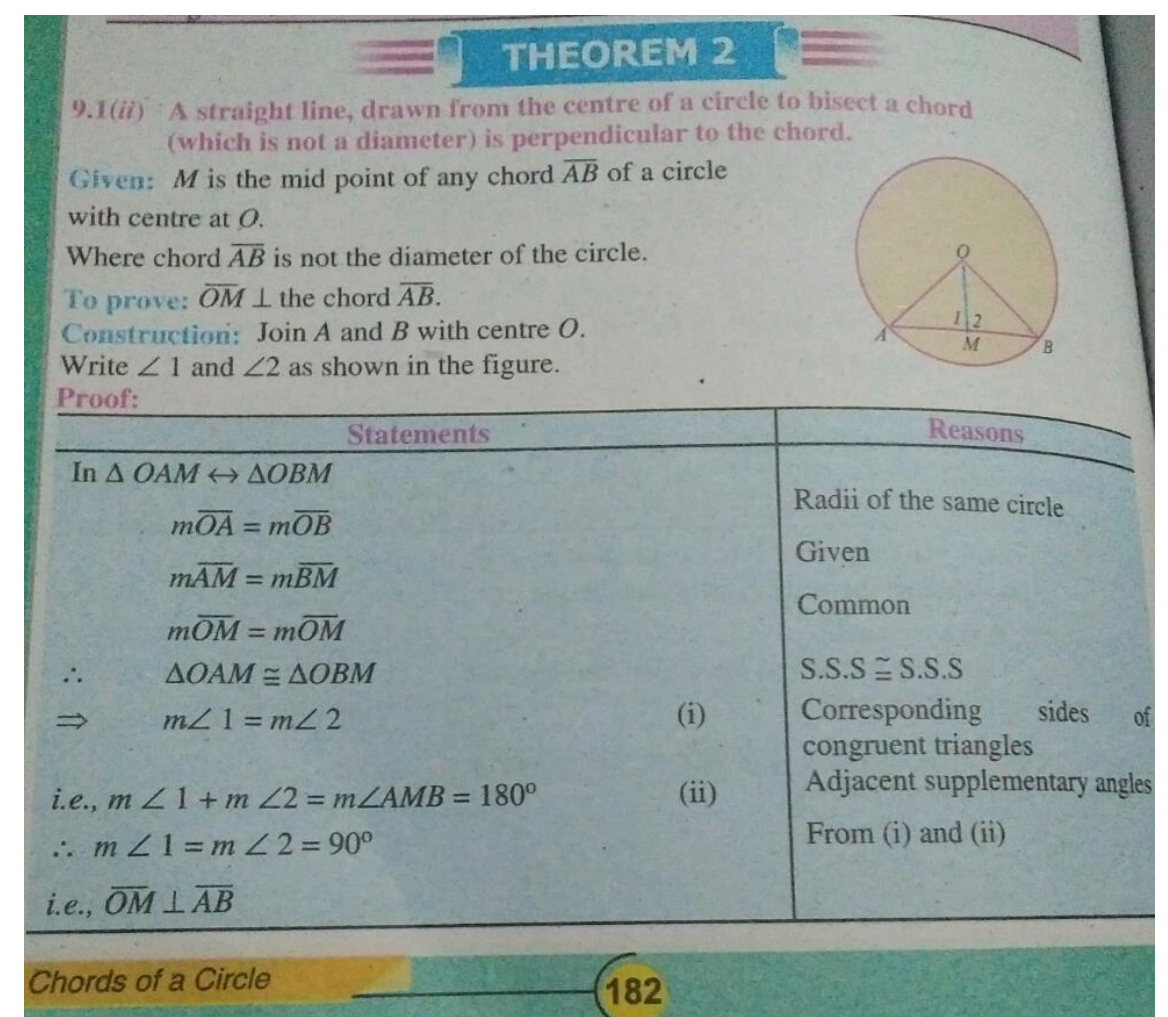

Figure 3. Proof of a Geometric Theorem showing Lack of Learning Experiences in Textbook. Reprinted from Mathematics 10 science group (p. 182), by M. Habib, A. Ali, A. R. Khan, and A. Moeen, 2013, Lahore: Ilmi Kitab Khana. Copyright 2013 by the Ilmi Kitab Khana

This inadequacy might be attributed to the curriculum document for not demanding the learning experiences for the students. That is probably the reason that even the SLOs like, applying a mathematical concept in daily life, are dealt with, like an ordinary mathematical sum that students can hardly relate to their daily life experiences. Some examples are shown in the figures 4 to 6 that are the snapshots of the textbooks. 


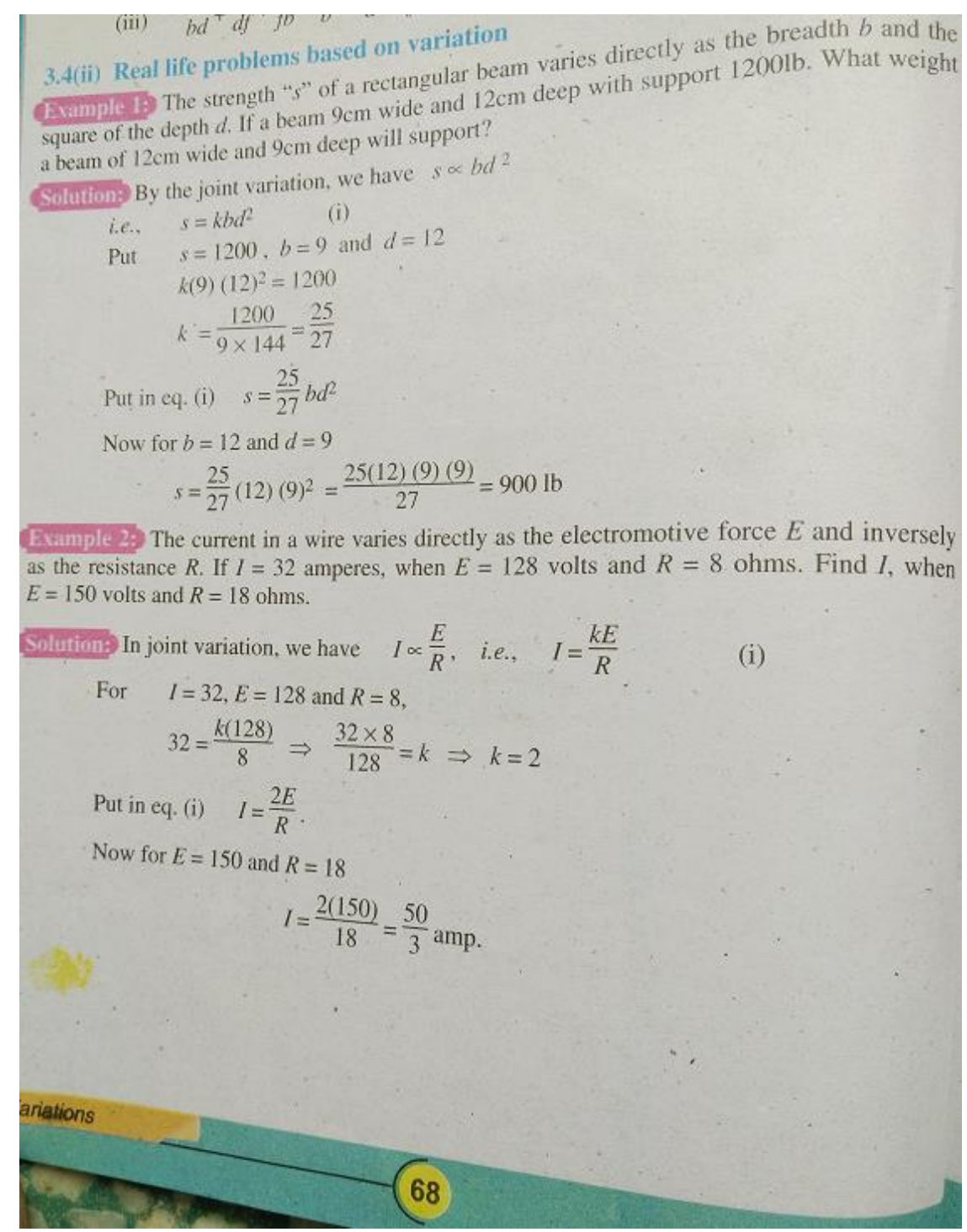

Figure 4. Explanation of Application of Variation in Real life. Reprinted from Mathematics 10 science group (p. 68), by M. Habib, A. Ali, A. R. Khan, and A. Moeen, 2013, Lahore: Ilmi Kitab Khana. Copyright 2013 by the Ilmi Kitab Khana 


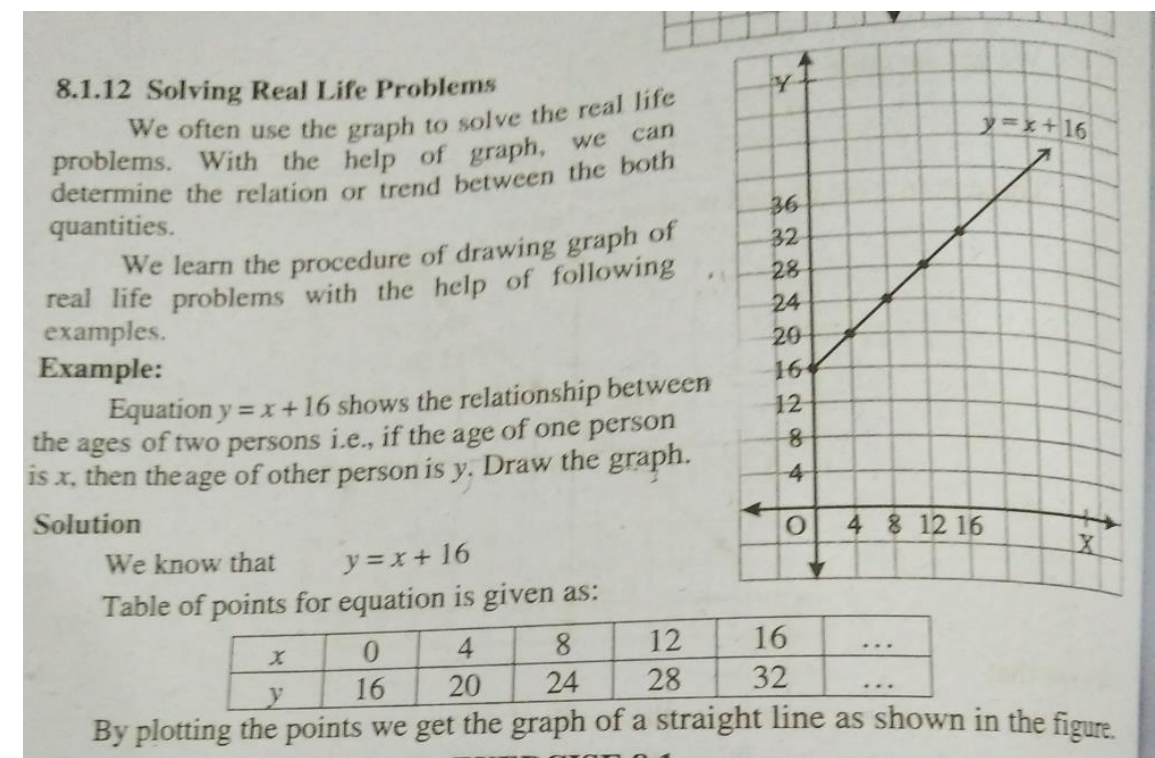

Figure 5. Explanation of Application of Graph in Real Life. Reprinted from Mathematics 9 science group (p. 156), by K. H. Dar and I. U. Haq, 2012, Lahore: Caravan Book House. Copyright 2012 by the Caravan Book House

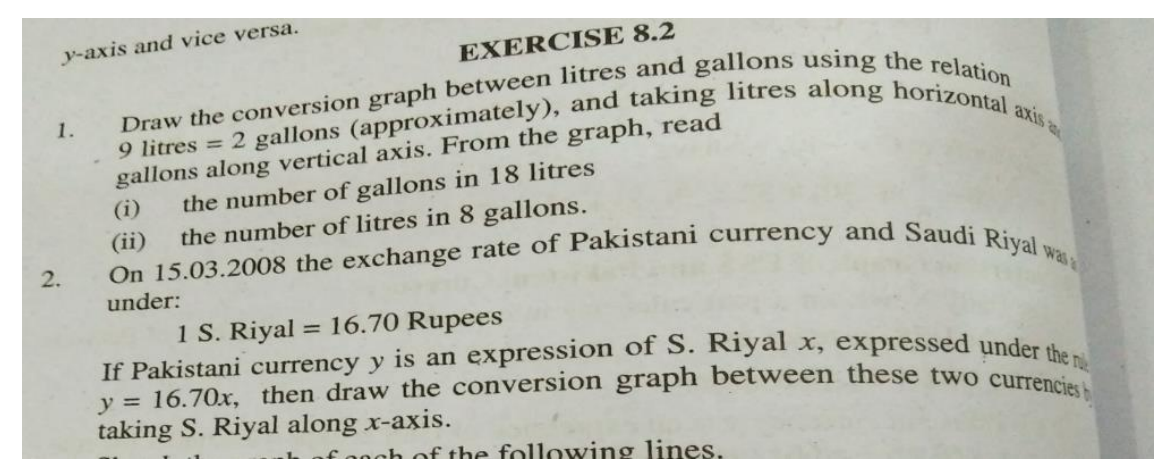

Figure 6. Exercise of Application of Graph in Real Life. Reprinted from Mathematics 9 science group (p. 164), by K. H. Dar and I. U. Haq, 2012, Lahore: Caravan Book House. Copyright 2012 by the Caravan Book House

In figures 4 and 5 for instance, so called daily life problems are described with the help of mathematical equations and it is a known fact that students don't face daily life problems in the form of mathematical equations. Moreover, students are offered the practice of applying different mathematical concepts in daily life in the same style i.e. the problems to be solved are described with the help of mathematical 
equations. Instead of involving students in the activities like "finding the height of a tree/ a building by measuring the angle of elevation with a clinometer" (Singapore Ministry of Education, 2012) the secondary mathematics textbooks offer couple of examples to explain the algorithm of calculating the angle of elevation- as observable from textbook by Habib et al. (2013, pp.22-24)- and then students are asked to practice the problems like "find the angle of elevation of the sun if a 6 feet man casts a 3.5 feet shadow" (Habib et al., 2013).

From the review of both the secondary mathematics textbooks, it is determinable that in these textbooks the so called learning activities designed against the SLOs are the procedures or algorithms of solving sums. That procedure or algorithm is explained with the help of a few examples and then an exercise i.e. a set of sums is offered to practice the same algorithm. This exercise or the set of sums comprises the sums matching with the problem/problems used to explain the corresponding algorithm. So no matter whether it is derivation of distance formula explained in textbook by Dar \& Haq (2012, p.168) or proving the properties of cube root of unity given in the textbook by Habib et al. (2013, pp.22-24), they only provide the students the procedural knowledge i.e. knowledge of any rule or law and its application. "The ability to recite a rule or set of procedures is "information learning"; the ability to apply a rule or procedure to a routine single-variable situation is 'application'. Neither of these skills involve higher order thinking" (King, Goodson, \& Rohani, 1998).

\section{Conclusions}

It was learnt that $73 \%$ of SLOs are of DOK level 1 and don't challenge students for mental processing. There are less number of SLOs of DOK level 2 and 3 in grade $X$ as compared to grade IX.

It is also noticeable from the Table 1 that the secondary school curriculum for mathematics is completely void of any SLO of DOK level 4. Any SLO in the secondary school mathematics curriculum doesn't seem to involve students in the Level 4 activities like designing experiments, synthesizing, critiquing etc.

The categories of DOK of Level 2 as stated in the Table 2, share a common characteristic- that is- "engagement of some mental processing beyond a habitual response" (Kentucky Department of Education, 2007). Activities like deriving a formula or proving a geometrical theorem 
qualify as a level 2 activity if they require a student to select appropriate concepts and procedures that involve fairly enough mental processing. But the format of the textbooks, however, doesn't seem to support such a challenging classroom experience that is a must for improving cognitive and metacognitive process skills (Ministry of Education [MoE], 2012): the building blocks of HOTS.

In brief, virtually no practice of mental processing is offered to students in these textbooks. For example, the learning activities in these textbooks don't help students practice 'converting a daily life problem in mathematical equation'. Those who designed the mathematics curriculum of Pakistan most likely have extracted this idea of designing SLOs like daily life application of mathematical concepts in the light of other curriculums being used in the world but this curriculum or textbooks were found void of the corresponding learning experiences as offered by those curriculums. So it is not difficult to infer that regardless of the apparent look of an SLO relating to HOTS, it is simply the "recall of information" and is of DOK Level 1 (Norman Webb, personal communications, October 5, 2014).

\section{Recommendations}

i. Instead of too many SLOs with $73 \%$ of the SLOs to be of DOK level 1 , it is suggested to adopt "fewer, higher and deeper" (DarlingHammond et al., 2013, p2) approach in the making of SLOs.

ii. There should be more number of HOTS in higher grade (i.e. grade X) than lower one (grade IX).

iii. It is suggested to incorporate the level 4 SLOs in the curriculum. The number of level 3 SLOs should also be increased.

iv. In the light of international practices, it is suggested to integrate the learning experience/applied curriculum with the list of SLOs.

v. It is suggested to include activities that challenge students' cognition instead of algorithms of solving sums. 


\section{References}

Anderson, D. L., \& Mills, A. (2015). Depth of knowledge of american elementary pre-service teachers' social studies lessons. Journal of Studies in Education, 5(1), 65-73. doi:10.5296/jse.v5i1.7023

Churches, A. (2009). Bloom's digital taxonomy. Retrived December 22,2018 from http://www.ccconline.org/wpcontent/uploads/2013/11/Churches_2008_DigitalBloomsTaxonomy Guide.pdf

Council of Chief State School Officers, (2002). Models for alignment analysis and assistance to states. Retrieved from https://secure.wceruw.org/seconline/Reference/AlignmentModelsfor StateAssist02.pdf

Dar, K. H., \& Haq, I.-u. (2012). Mathematics 9 (science group). Lahore, Pakistan: Carvan Book House.

Darling-Hammond, L. H. (2013). Criteria for high-quality assessment. Stanford. CA: Stanford Center. Retrieved October 19, 2015, from https://edpolicy.stanford.edu/sites/default/files/publications/criteriahigher-quality-assessment_2.pdf

Forehand, M. (2010). Bloom's taxonomy. From emerging perspectives on learning, teaching and technology. Athens: University of Georgia.

Habib, M., Ali, A., Khan, A. R., \& Moeen, M. (2013). Mathematics 10 (science group). Lahore, Pakistan: Ilmi Kitab Khana.

- Haladyna, T. M., \& Downing, S. M. (2006). Handbook of test development. Abingdon, UK:Routledge

Harding, J. L., \& Hbaci, I. (2015). Evaluating pre-service teachers math teaching experience from different perspectives. Universal Journal of Educational Research, 3(6), 382-389.

Healey, M. (2005). Linking research and teaching exploring disciplinary spaces and the role of inquiry-based learning. In R. Barnett (Ed.), Reshaping the university: New relationships between research, 
scholarship and teaching (pp. 67-78). Retrieved from https://pdfs.semanticscholar.org/6274/989392ec7f61bf0dc68e2719bd 2789cd619b.pdf

Hess, K. K., Carlock, D., Jones, B., \& Walkup, J. R. (2009). What exactly do "fewer, clearer, and higher standards" really look like in the classroom? using cognitive rigor matrix to analyze curriculum, plan lessons, and implement assessments. Detroit, MI: Concil of Chief State School Officers (CCSSO).

Hess, K. K., Jones, B. S., Carlock, D., \& Walkup, J. R. (2009). Cognitive rigor: Blending the strengths of Bloom's taxonomy and Webb's depth of knowledge to enhance classroom-level processes. Retrieved from the ERIC database. (ED517804)

Hofer, C. (2015). The introduction of the Singapore bar model in year 1 problem solving: A personal reflection. The STeP Journal, 2(2), 107117.

Kentucky Department of Education. (2007). Support materials for core content for assessment: Version 4.1. Retrieved from https://www.veronaschools.org/cms/lib/NJ01001379/Centricity/Dom ain/17/cca_dok_support_808_science.pdf

King, F. J., Goodson, L., \& Rohani, F. (1998). Higher order thinking skills. Tallahassee, FL: Center for Advancement of Learning and Assessment.

Krathwohl, D. R. (2002). A revision of Bloom's taxonomy: An overview. Theory Into Practice, 41(4), 212-218. Retrieved from https://www.depauw.edu/files/resources/krathwohl.pdf

Mahmood, K. (2010). Textbook evaluation in Pakistan: Issue of conformity to the national curriculum guidelines. Bulletin of Education and Research, 32(1), 15-36.

Marzano, R. J. (2006). The new taxonomy of educational objectives. Thousand Oaks, CA: Corwin.

Ministry of Education (2006). National Curriculum for Mathematics. Islamabad, Pakistan: Ministry of Education. 
Ministry of Education (2012). Mathematics syllabus secondary one to four express course normal(academic) course. Singapore: Ministry of Education.

Musfiqi, S., \& Jailani. (2015). Developing mathematics instructional materials oriented to character and higher order thinking skills (HOTS) . Paper presented at the International Conference on Research, Implementation and Education of Mathematics and Sciences 2015. Yogyakarta, Indonesia: Retrieved from http://eprints.uny.ac.id/22981/1/ME\%20-\%2010.pdf

Patterson, L. G., Musselman, M., Rowlett, J. (2013). Using the depth of knowledge model to create high school mathematics assessments-research. Kentucky Journal of Excellence in College Teaching and Learning, 11(4), 39-45.

Skinner, R., \& Feder, J. (2014). Common core state standards and assessments: background and issues. Retrieved October 19, 2015, from http://fas.org/sgp/crs/misc/R43711.pdf

Ursani, A. A., Memon, A. A., \& Chowdhry, B. S. (2014). Bloom's taxonomy as a pedagogical model for signals and systems. International Journal of Electrical Engineering Education, 51(2), 162-173.

Webb, N. L. (1997). Criteria for alignment of expectations and assessments in mathematics and science education. Washington, DC: Council of Chief State School Officers.

Webb, N. L. (1999). Alignment $f$ science and mathematics standards and assessments in four states. Washington, DC: National Institute for Science Education University of Wisconsin-Madison.

Webb, N. L. (2002). An analysis of the alignment between mathematics standards and assessments for three states. Paper presented at the Annual Meeting of the American Educational Research Association. New Orleans, LA. Retrieved from http://facstaff.wceruw.org/normw/AERA\%202002/Alignment\%20A nalysis\%20three\%20states\%20Math\%20Final\%2031502.pdf 
Webb, N. L. (2005). Web alignment tool: Training manual. Retrieved from Wisconsin Center of Education Research website http://watv2.wceruw.org/Training\%20Manual\%202.1\%20Draft\%200 91205.doc

Webb, N. L. (2007). Issues related to judging the aligmnent of curriculum. Applied Measurement In Education, 20(1), 7-25.

\section{Citation of this Article:}

Gulzar, K \& Mahmood, N. (2018). Appraising adequacy of standard based curriculum 2006 and allied secondary school mathematics textbooks for higher order thinking skills (HOTS) in the Punjab, Pakistan. Pakistan Journal of Education, 35 (3), 01-18. 